\title{
Networking the environment: social network analysis in environmental management and local ecological knowledge studies
}

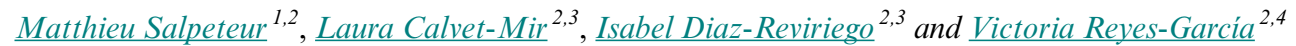

Key Words: local ecological knowledge; natural resource management; seed exchange networks; social network analysis

\section{INTRODUCTION}

Social network analysis (SNA) is grounded in a relational perspective. It conceives the system under study as a network composed of a set of nodes and ties, which can be represented and analyzed through a variety of mathematical tools (Wasserman and Faust 1994, Scott 2013).

Since it first emerged in the 1930s, SNA has extensively grown across multiple research fields, including physics, biology, and history, among others (Borgatti et al. 2009). In the social sciences, the distinctive contribution of SNA has been to shift the analytical focus from individual characteristics or social categories, which were at the center of classical social science research, to the patterns of relations in which individuals or groups are embedded (White and Johansen 2005, Borgatti et al. 2009). This relational perspective has allowed the development of a rich body of research, tackling key questions in the social sciences. For example, SNA researchers have made important contributions to our understanding of how power and influence are distributed in a given social structure (Bonacich 1987), of how social ties of different intensity explain social systems' dynamics (e.g., Burt 2004), of the nature of the relations between social structures and individual agency (Archer 1982, Emirbayer and Goodwin 1994), and of the importance of shared characteristics in the formation of social clusters (the "homophily effect"; see McPherson et al. 2001). These theoretical advances have been of specific interest among scholars studying natural resources management, because they are dealing with the study of social-ecological systems in which complex social dynamics and interactions are taking place. SNA indeed offers some adequate theoretical and methodological frames to uncover the ways in which heterogeneous groups of actors interact, collaborate, exchange information and materials, and mobilize their social capital, all key aspects of natural resources management. Application of SNA in this field of research has given birth to a wealth of studies, which we will present below.

In this Special Feature, we gather contributions building on this line of research that specifically focus on three themes: (1) how SNA helps us explain natural resources governance, (2) how it helps us understand the circulation and local management of plant propagative materials, and (3) how it helps us understand the transmission of local ecological knowledge. Within each of these thematic areas, the contributions assembled here provide some new theoretical and methodological insights, based on case studies covering a large range of geographical and thematic areas. Because all readers may not be familiar yet with SNA, we propose a brief introduction to SNA in the following paragraph, before introducing the contributions to the special feature.

\section{SNA: PRIMARY CONCEPTS AND METHODS}

In SNA, social networks are conceptualized as including (1) a set of nodes that represent individuals or groups, also named vertices/ nodes; and (2) a set of ties that represent the types of relations linking these nodes, also named links or ties. Typical examples of ties are relations of friendship, common interest, financial exchanges, or exchanges of knowledge or material goods. The structure of the network can be analyzed at three levels: the individual level (e.g., looking at how central an individual is within the network), the dyadic level (i.e., identifying microstructures in which pairs of individuals are embedded), and the network level (i.e., analyzing specific network properties, such as density, modularity, or connectivity between elements). Depending on the research objectives, researchers can either focus on whole networks (or socio-centric networks) or on personal networks (or ego-centric networks). Socio-centric networks represent a bounded set of actors between which all interactions are mapped and integrated in the analysis, whereas ego-centric networks represent the respective relational communities of a set of actors, who are not necessarily connected between themselves. An extensive literature regarding these methodological aspects is available (Wasserman and Faust 1994, Borgatti et al. 2013, Scott 2013). The contributions gathered in this Special Feature offer to the reader a large panorama of methodological approaches to SNA, showcasing the flexibility of this approach and its potential fitness to a wide array of research questions and case studies. A common feature of many of these contributions is to use mixed methods that associate SNA with a rich qualitative, ethnographic data collection, an approach that allows a detailed analysis of the complex dynamics that underlie social networks, be they related to information transmission, resource governance, or seed circulation.

SNA and the governance of natural resources

SNA has been extensively used to study natural resources governance and management (Crona and Hubacek 2010, Bodin and Prell 2011). This is so because the management of natural resources typically involves a large variety of actors, who are embedded in various institutions and interact at different scales

${ }^{1}$ Centre d'Écologie Fonctionnelle et Évolutive (CEFE), CNRS UMR 5175, ${ }^{2}$ Institut de Ciència i Tecnologia Ambientals (ICTA), Universitat Autònoma de Barcelona, ${ }^{3}$ Internet Interdisciplinary Institute (IN3), Universitat Oberta de Catalunya, ${ }^{4}$ Institució Catalana de Recerca i Estudis Avançats (ICREA) 
and in heterogeneous ways, e.g., through relations of power, mutual help, etc. So far, the use of SNA has resulted in four major contributions to our understanding of natural resources governance and management.

First, research on SNA and natural resource management has shown the importance of examining the characteristics of specific individuals in relation to network structure (i.e., centrality, brokering ability) to understand the functioning of stakeholders' networks (Prell et al. 2009). For example, Isaac et al. (2014) analyzed the role of Ghanian migrant famers in the transmission of agroecosystem management practices. Their results suggest that there are diffuse networks through which information is transmitted and whose cohesion depends on a few strategic bridging ties initiated by migrant farmers, who are thus centrally positioned to exchange agroecosystem management practices between geographically and socially distant groups.

Second, SNA research has also addressed the specific patterns of interindividual connections and the processes (i.e., collaboration, decision making, distribution of political power, or diffusion of shared perceptions) that tie stakeholders in a network (Rico Garcia-Amado et al. 2012). For example, Barnes-Mauthe et al. (2015) examined the correlates of social capital among individuals in Hawaii's longline fishery. According to their findings, ethnicity is the strongest predictor of social capital, a finding that largely explains why industry leaders and formal fishery representatives are generally not well connected. Research on the specific processes that tie actors in a network is important because it might help unravel the existence of power asymmetries in networks and the implications of such asymmetries in the management of natural resources (Crona and Bodin 2010).

The third contribution of research applying SNA to study natural resources governance and management has been to reveal some of the structural characteristics of the networks that connect actors involved in natural resource management, thus allowing predictions to be made on how such characteristics might affect resource management (Bodin and Crona 2009, Newig et al. 2010).

Finally, SNA has also highlighted the multiscalar nature of natural resource governance, especially aiming to connect local management to higher scales of policy and planning (Cohen et al. 2012, Beilin 2013). For example, in the Solomon Islands, Cohen et al. (2012) examined a governance network involved in adaptive comanagement of coastal ecosystems. The network examined was composed of actors at several scales, from local communities to nongovernmental organizations and government agencies, all involved in the adaptive comanagement of coastal ecosystems. Their findings suggest that geographic, logistical, and institutional barriers to cross-scale coordination and learning might hamper coordination and learning among management actors. The analysis allows understanding of management failures, with potential implications for the design of better management tools.

Thus, these results suggest that SNA holds a great potential to enhance natural resource governance. On one hand it helps us to understand how complex social interactions between the stakeholders and across scales affect the ways that natural resources are dealt with, and on the other hand it may be used to provide support for the design and the implementation of management plans, to "weave" relational ties between stakeholders that would improve natural resources governance (Vance-Borland and Holley 2011).

The contributions gathered in this Special Feature further contribute to these research lines, mostly through a focus on the patterns of communication or interactions between stakeholders involved in activities related to natural resources governance. Calvet-Mir et al. (2015) analyzed the informal communication network between the stakeholders related to the governance of a natural park in Spain. By comparing the informal exchanges of information between a large set of institutional and noninstitutional actors with the formal participatory bodies of the natural park, they show how the social network approach enables identification of key stakeholders to be included in participatory bodies, thus potentially helping to improve participative governance of protected areas. In a quite different setting, Hauck et al. (2016) used SNA to identify the key actors in the implementation of the European Union green infrastructure strategy in Germany. Their case study specifically relates to local and regional-level actors involved in agricultural biodiversity governance. Using the Net-Map tool, they adopted a participatory perspective and grounded their study on qualitative data (e.g., narratives providing descriptions of the ties) and quantitative data (e.g., statistical analyses of networks structures and actors' positions). Through the analysis of this rich body of data, they provide a detailed description of the patterns of interaction and information flows between local and regional actors, and highlight key factors potentially shaping actors' behaviors or impeding behavioral change, such as social pressure. Tindall and Robinson (2017) studied the personal networks of environmental activists engaged with the protection of the Clayoquot Sound forest area, Canada. They grounded their work on previous studies that have shown that interpersonal connections play a key role in explaining the participation of individuals in social movements: The more connections an individual has to activists, the more likely it is that he/she will become involved him/herself. In this line, they used the case study in Canada to compare the explanatory power of variables related to informants' social connections (ego-network centrality) versus individual-level characteristics (values and attitudes, sociodemographic variables). Their results show that, although some nonrelational variables can help explain individual engagement, the individuals' social environment has a stronger explanatory power, thus bringing a new understanding of the social dynamics underpinning environmental movements. Last, Oubenal et al. (2017) propose a study of the advice network among the participants in the stakeholders' days of the International Platform for Biodiversity and Ecosystem Services (IPBES), which took place in Turkey in 2013. Using discourse analysis combined with ethnographic observations and SNA, they studied the structure of the participants' community and the patterns of information exchanges between these participants in relation to the types of involvement, i.e., collaborative or dissenting voicing, that the participants displayed. The analysis performed enabled Oubenal et al. to describe and analyze the quite complex internal dynamics underlying the functioning of the stakeholders' assembly and even to propose options for further improvement of the inclusion and participation of heterogeneous nonstate actors in the IPBES. 


\section{SNA and the circulation of plant propagative materials}

One particular area in which SNA has revealed itself as very popular is the study of plant material circulation. A growing body of research indicates that cultural diversity, social differentiation, gender relations, and agrobiodiversity management are intertwined (Howard 2003, Reyes-García et al. 2010, Leclerc and Coppens d'Eeckenbrugge 2011, Labeyrie et al. 2014). Results from such research highlight the importance of understanding the social context of plant materials' (e.g., seeds or stems) exchanges, as well as the cultural processes leading to the selection of plants and germplasm for in situ agrobiodiversity conservation (Ellen and Platten 2011, Pautasso et al. 2012, Coomes et al. 2015). In this context, SNA has proved to be a powerful tool for analyzing the flow of seeds and crop varieties among farmers and gardeners (Thomas et al. 2012, Kawa et al. 2013, Poudel et al. 2015). For example, Calvet-Mir et al. (2012) explored the seed exchange network of gardeners in the Catalan Pyrenees, Spain, and found that people with higher centrality in the network conserved more local landraces and had more local landrace knowledge than people who were less central in the network. In a similar study among gardeners in Spain, Reyes-García et al. (2013) found that the number of contacts held by an individual in the germplasm exchange network was positively associated with her/his agroecological knowledge. Interestingly, other studies have also shown that social networks can constrain varietal distribution, which may in turn result in lowering crop diversity in agricultural communities. For example, the study by Kawa et al. (2013) among caboclos' in Brazilian Amazonia showed that households holding a more central position in the local manioc exchange network were those who cultivated greater areas of manioc, and not those who maintained a greater diversity in manioc varieties. In sum, results from the study of the social networks underpinning plant materials' exchanges reveal that the specific social and cultural context in which agrobiodiversity exchanges take place is important in understanding the actual distribution of crop varieties and seeds, because social networks might either support or constrain agrobiodiversity circulation. Such findings might inform effective agrobiodiversity conservation policies.

Four contributions to this Special Feature provide detailed studies of exchange networks of plant propagative material. The contribution by Wencélius et al. (2016) challenges the standard approach in seed circulation studies that considers the household as unit of analysis. They studied the intra-household exchanges of seeds in a smallholder farming community from northern Cameroon and show that intra-household exchange patterns vary widely from one household to the other, depending on the household composition, e.g., polygynous versus monogynous households. For example, they found that wealthier households tend to display a more diverse set of seed sources than poorer households, because of higher coresident diversity and more intra-household seed transactions. In a neighboring region of Cameroon, Violon et al. (2016) study the temporal evolution of seed circulation networks. By comparing seed supply networks in a "normal" and a dry year, the authors show that farmers tend to seek seeds in a different way depending on the environmental constraints: In exceptional conditions, the seed supply networks tend to be much more extended spatially and their composition varies, with woman-related kin networks becoming more important. These authors also reflect on the methodological biases that tend to make the researcher blind to differences between the types of relations that are mapped through SNA, for example, when temporary relations are mistakenly recorded as equivalent to long-lasting ones. Such methodological insights should be of interest to a large audience. In another contribution to this topic, Thomas and Caillon (2016) use a socio-centric network approach to analyze the circulation of three types of food plants in a village in Vanuatu. Using very rich ethnographic material describing local plant categories and local social organization, associated with advanced statistical analyses, the authors show that the two main factors affecting the circulation of plant materials are farmers' social status (with higher-rank individuals tending to give more plants) and the biocultural value given to plants. Last, in their contribution Díaz-Reviriego et al. (2016) map the social exchange of medicinal plant material and knowledge among gardeners in two villages of a foragerhorticulturalist society of Bolivian Amazonia, the Tsimane'. The study analyzes how these interactions affect the richness of medicinal plants in homegardens and the local ethnomedicinal knowledge of gardeners. Through this approach, the authors show that plant richness in homegardens is partly shaped by social organization, where gender and kinship relations are fundamental aspects that patterns daily social interactions.

SNA and the transmission of local ecological knowledge

The importance of analyzing social relations and social structure to understand cultural knowledge transmission was highlighted in the anthropological literature decades ago, although without specifically using SNA (e.g., Cavalli-Sforza and Feldman 1981, Boster 1986). Drawing on this body of literature, researchers interested in the transmission and distribution of local environmental knowledge have recently started to apply SNA for tracing the pathways of intra-cultural and intercultural knowledge transmission. Such research has brought some important insights. First, it has shown that the patterns of knowledge transmission are much more complex than usually expected and extend beyond the categories or social groups that are usually included in knowledge transmission studies, such as kin-based groups. For instance, in a case study focusing on a community of fishers along coastal Kenya, Crona and Bodin (2006) have shown that ecological knowledge transmission mainly occurred within occupation-related groups, in this case, fishermen using the same gear.

A second key finding of applying SNA to the study of local knowledge transmission relates to our understanding of how individuals select knowledge sources and seek information. In this line, the study by Henrich and Broesch (2011) among Fijian villagers shows evidence of the importance of selective learning biases in knowledge transmission, where people are more likely to learn from the ones perceived as more successful or knowledgable about fishing, medicinal plants, and yam cultivation. In a study along the same line, Haselmair et al. (2014) used a personal network approach to map the different sources (people, but also books, the Internet, and the like) involved in food and medicinal plant knowledge transmission among Tyrolean migrants in Australia, Brazil, and Peru. Their results suggest that the selection of sources from which to seek knowledge depends on individuals' socioeconomic conditions and the type of knowledge that the individual aims to acquire: Although people, i.e., relatives and friends, play an important role in remote 
areas (Brazil and Peru), other sources, i.e, the Internet or the mass media, grow in importance in other contexts. A last contribution of this type of work has been to highlight the importance of (1) an individual's position in a network and (2) the structural characteristics of the network to better understand local ecological knowledge transmission. In this line, Hopkins (2011) and Calvet-Mir et al. (2012) explore the effect of individuals' centrality in exchange networks on the knowledge they hold. Although their work was conducted in two different contexts, they both show that the more central an individual is, the more knowledgeable he/she tends to be.

This Special Feature includes one contribution pertaining to this research field. Salpeteur et al. (2016) used SNA to identify the social groups that potentially affect the transmission of local environmental knowledge related to pastoralist activities, among the Rabari transhumant shepherds of Western India. Through SNA, the authors mapped two informal networks (friendship and migration partnership), to which they applied clustering methods to extract groups of highly connected individuals. They then compared the local ecological knowledge held by these groups with quantitative tools. Their results show that, whereas friendship relations do not appear to affect knowledge exchanges, migration partnership is a strong driver of intra-cultural knowledge transmission, because groups of comigrants tend to hold similar knowledge. The social organization of migration, closely related to the nomadic way of life, is shown to shape the patterns of intracultural variations of local ecological knowledge, thus bringing new understandings of the dynamics of local ecological knowledge in the context of seminomadic pastoralist communities.

Altogether, the articles presented in this Special Feature offer a wide panorama of current applications of SNA across a variety of research lines, case studies, and theoretical and methodological approaches. They show that SNA is a flexible tool that provides a different and useful perspective on complex social dynamics in relation to environmental management. We hope that these contributions will inspire new applications and developments of this approach in future research.

Responses to this article can be read online at: http://www.ecologyandsociety.org/issues/responses. $\mathrm{php/8790}$

\section{Acknowledgments:}

Preliminary versions of the papers collected in this special feature were presented in two congress sessions organized by the editors. The first session, in which the four editors collaborated, was titled "Networking the Environment: Social Network Analysis in Environmental Management." The session was held during the first European Conference on Social Networks (EUSN; 1-4 July 2014) in Barcelona. The second session, organized by Matthieu Salpeteur (with A. Jain) under the title "Traditional Ecological Knowledge" was held during the 14th Congress of the International Society of Ethnobiology in Bhutan (1-7 June 2014). The guest editors are grateful to all involved authors and reviewers for their time and effort and to J. L. Molina for comments on a previous version of this text.
We acknowledge the financial support of SimulPast (CSD 2010-00034) and LEK (ERC-FP7, Grant Agreement 261971). This work contributes to the ICTA Unit of Excellence (MinECo, MDM2015-0552).

\section{LITERATURE CITED}

Archer, M. S. 1982. Morphogenesis versus structuration: on combining structure and action. British Journal of Sociology 33 (4):455-483. http://dx.doi.org/10.2307/589357

Barnes-Mauthe, M., S. A. Gray, S. Arita, J. Lynham, and P. Leung. 2015. What determines social capital in a social-ecological system? Insights from a network perspective. Environmental Management 55:392-410. http://dx.doi.org/10.1007/s00267-014-0395-7

Beilin, R., N. T. Reichelt, B. J. King, A. Long, and S. Cam. 2013. Transition landscapes and social networks: examining on-ground community resilience and its implications for policy settings in multiscalar systems. Ecology and Society 18(2):30. http://dx.doi. org/10.5751/es-05360-180230

Bodin, Ö., and B. I. Crona. 2009. The role of social networks in natural resource governance: what relational patterns make a difference? Global Environmental Change 19:366-374. http://dx. doi.org/10.1016/j.gloenvcha.2009.05.002

Bodin, Ö., and C. Prell, editors. 2011. Social networks and natural resource management. Uncovering the social fabric of environmental governance. Cambridge University Press, Cambridge, UK. http://dx.doi.org/10.1017/cbo9780511894985

Bonacich, P. 1987. Power and centrality: a family of measures. American Journal of Sociology 92(5):1170-1182. http://dx.doi. org/10.1086/228631

Borgatti, S. P., M. G. Everett, and J. C. Johnson. 2013. Analyzing social networks. Sage, Thousand Oaks, California, USA.

Borgatti, S. P., A. Mehra, D. J. Brass, and G. Labianca. 2009. Network analysis in the social sciences. Science 323 (5916):892-895. http://dx.doi.org/10.1126/science.1165821

Boster, J. S. 1986. Exchange of varieties and information between Aguaruna manioc cultivators. American Anthropologist 88:429-436. http://dx.doi.org/10.1525/aa.1986.88.2.02a00100

Burt, R. S. 2004. Structural holes and good ideas. American Journal of Sociology 110:349-399. http://dx.doi.org/10.1086/421787

Calvet-Mir, L., M. Calvet-Mir, J. Luis Molina, and V. ReyesGarcía. 2012. Seed exchange as an agrobiodiversity conservation mechanism. A case study in Vall Fosca, Catalan Pyrenees, Iberian Peninsula. Ecology and Society 17(1):29. http://dx.doi. org/10.5751/ES-04682-170129

Calvet-Mir, L., S. Maestre-Andrés, J. Molina, and J. van den Bergh. 2015. Participation in protected areas: a social network case study in Catalonia, Spain. Ecology and Society 20(4):45. http://dx.doi.org/10.5751/ES-07989-200445

Cavalli-Sforza, L. L., and M. W. Feldman. 1981. Cultural transmission and evolution: a quantitative approach. Princeton University Press, Princeton, New Jersey, USA.

Cohen, P. J., L. S. Evans, and M. Mills. 2012. Social networks supporting governance of coastal ecosystems in Solomon Islands. 
Conservation Letters 5:376-386. http://dx.doi.org/10.1111/ j.1755-263X.2012.00255.X

Coomes, O. T., S. J. McGuire, E. Garine, S. Caillon, D. McKey, E. Demeulenaere, D. Jarvis, G. Aistara, A. Barnaud, P. Clouvel, L. Emperaire, S. Louafi, P. Martin, F. Massol, M. Pautasso, C. Violon, and J. Wencelius. 2015. Farmer seed networks make a limited contribution to agriculture? Four common misconceptions. Food Policy 56:41-50. http://dx.doi.org/10.1016/j.foodpol.2015.07.008

Crona, B., and Ö. Bodin. 2006. What you know is who you know? Communication patterns among resource users as a prerequisite for co-management. Ecology and Society 11(2):7. http://dx.doi. org/10.5751/ES-01793-110207

Crona, B., and Ö. Bodin. 2010. Power asymmetries in small-scale fisheries: a barrier to governance transformability? Ecology and Society 15(4):32. http://dx.doi.org/10.5751/ES-03710-150432

Crona, B., and K. Hubacek, guest editors. 2010. Social network analysis in natural resource governance. Ecology and Society Special Feature 48. http://www.ecologyandsociety.org/issues/ view.php?sf $=48$

Díaz-Reviriego, I., L. González-Segura, Á. FernándezLlamazares, P. L. Howard, J. Molina, and V. Reyes-García. 2016. Social organization influences the exchange and species richness of medicinal plants in Amazonian homegardens. Ecology and Society 21(1):1. http://dx.doi.org/10.5751/ES-07944-210101

Ellen, R., and S. Platten. 2011. The social life of seeds: the role of networks of relationships in the dispersal and cultural selection of plant germplasm. Journal of the Royal Anthropological Institute 17:563-584. http://dx.doi.org/10.1111/j.1467-9655.2011.01707. $\underline{x}$

Emirbayer, M., and J. Goodwin. 1994. Network analysis, culture, and the problem of agency. American Journal of Sociology 99 (6):1411-1454. http://dx.doi.org/10.1086/230450

Hauck, J., J. Schmidt, and A. Werner. 2016. Using social network analysis to identify key stakeholders in agricultural biodiversity governance and related land-use decisions at regional and local level. Ecology and Society 21(2):49. http://dx.doi.org/10.5751/ ES-08596-210249

Haselmair, R., H. Pirker, E. Kuhn, and C. R. Vogl. 2014. Personal networks: a tool for gaining insight into the transmission of knowledge about food and medicinal plants among Tyrolean (Austrian) migrants in Australia, Brazil and Peru. Journal of Ethnobiology and Ethnomedicine 10(1):1. http://dx.doi. org/10.1186/1746-4269-10-1

Henrich, J., and J. Broesch. 2011. On the nature of cultural transmission networks: evidence from Fijian villages for adaptive learning biases. Philosophical Transactions of the Royal Society B: Biological Sciences 366(1567):1139-1148. http://dx.doi. org/10.1098/rstb.2010.0323

Hopkins, A. 2011. Use of network centrality measures to explain individual levels of herbal remedy cultural competence among the Yucatec Maya in Tabi, Mexico. Field Methods 23(3):307-328. http://dx.doi.org/10.1177/1525822x11399400

Howard, P. L. 2003. Women and plants. Gender relations in biodiversity management and conservation. Pages 1-48 in P. L.
Howard, editor. Women and plants. Zed Press and Palgrave McMillan, London, UK, and New York, New York, USA.

Isaac, M. E., L. C. N. Anglaaere, D. S. Akoto, and E. Dawoe. 2014. Migrant farmers as information brokers: agroecosystem management in the transition zone of Ghana. Ecology and Society 19(2):56. http://dx.doi.org/10.5751/es-06589-190256

Kawa, N. C., C. McCarty, and C. R. Clement. 2013. Manioc varietal diversity, social networks, and distribution constraints in rural Amazonia. Current Anthropology 54:764-770. http://dx.doi. org/10.1086/673528

Labeyrie, V., B. Rono, and C. Leclerc. 2014. How social organization shapes crop diversity: an ecological anthropology approach among Tharaka farmers of Mount Kenya. Agriculture and Human Values 31(1):97-107. http://dx.doi.org/10.1007/ $\underline{\text { s10460-013-9451-9 }}$

Leclerc, C., and G. Coppens d'Eeckenbrugge. 2011. Social organization of crop genetic diversity. The $\mathrm{G} \times \mathrm{E} \times \mathrm{S}$ interaction model. Diversity 4(1):1-32. http://dx.doi.org/10.3390/d4010001

McPherson, M., L. Smith-Lovin, and J. M. Cook. 2001. Birds of a feather: homophily in social networks. Annual Review of Sociology 27:415-444. http://dx.doi.org/10.1146/annurev.soc.27.1.415

Newig, J., D. Güenther, and C. Pahl-Wostl. 2010. Synapses in the network: learning in governance networks in the context of environmental management. Ecology and Society 15(4):24. https://doi.org/10.5751/ES-03713-150424

Oubenal, M., M. Hrabanski, and D. Pesche. 2017. IPBES, an inclusive institution? Challenging the integration of stakeholders in a science-policy interface. Ecology and Society 22(1):11. https:// doi.org/10.5751/ES-08961-220111

Pautasso, M., G. Aistara, A. Barnaud, S. Caillon, P. Clouvel, O. T. Coomes, M. Delêtre, E. Demeulenaere, P. De Santis, T. Döring, L. Eloy, L. Emperaire, E. Garine, I. Goldringer, D. Jarvis, H. I. Joly, C. Leclerc, S. Louafi, P. Martin, F. Massol, S. McGuire, D. McKey, C. Padoch, C. Soler, M. Thomas, and S. Tramontini. 2012. Seed exchange networks for agrobiodiversity conservation. A review. Agronomy for Sustainable Development 33(1):151-175. http://dx.doi.org/10.1007/s13593-012-0089-6

Poudel, D., B. Sthapit, and P. Shrestha. 2015. An analysis of social seed network and its contribution to on-farm conservation of crop genetic diversity in Nepal. International Journal of Biodiversity 2015:e312621. http://dx.doi.org/10.1155/2015/312621

Prell, C., K. Hubacek, and M. Reed. 2009. Stakeholder analysis and social network analysis in natural resource management. Society \& Natural Resources 22(6): 501-518. http://dx.doi. org/10.1080/08941920802199202

Reyes-García, V., J. L. Molina, L. Calvet-Mir, L. Aceituno-Mata, J. J. Lastra, R. Ontillera, M. Parada, M. Pardo-de-Santayana, M. Rigat, J. Vallès, and T. Garnatje. 2013. "Tertius gaudens": germplasm exchange networks and agroecological knowledge among home gardeners in the Iberian Peninsula. Journal of Ethnobiology and Ethnomedicine 9:53. http://dx.doi. org/10.1186/1746-4269-9-53

Reyes-García, V., S. Vila, L. Aceituno-Mata, L. Calvet-Mir, T. Garnatje, A. Jesch. J. J. Lastra, M. Parada, M. Rigat, J. Vallès, 
and M. Pardo-de-Santayana. 2010. Gendered homegardens: a study in three mountain areas of the Iberian Peninsula. Economic Botany 64:235-247. http://dx.doi.org/10.1007/s12231-010-9124-1

Rico García-Amado, L., M. Ruiz Pérez, I. Iniesta-Arandia, G. Dahringer, F. Reyes, and S. Barrasa. 2012. Building ties: social capital network analysis of a forest community in a biosphere reserve in Chiapas, Mexico. Ecology and Society 17(3):3. http:// dx.doi.org/10.5751/es-04855-170303

Salpeteur, M., H. R. Patel, J. L. Molina, A. L. Balbo, X. RubioCampillo, V. Reyes-García, and M. Madella. 2016. Comigrants and friends: informal networks and the transmission of traditional ecological knowledge among seminomadic pastoralists of Gujarat, India. Ecology and Society 21(2):20. http://dx.doi. org/10.5751/ES-08332-210220

Scott, J. 2013. Social network analysis. Third edition. Sage, Thousand Oaks, California, USA.

Thomas, M., and S. Caillon. 2016. Effects of farmer social status and plant biocultural value on seed circulation networks in Vanuatu. Ecology and Society 21(2):13. http://dx.doi.org/10.5751/ ES-08378-210213

Thomas, M., E. Demeulenaere, J. C. Dawson, A. R. Khan, N. Galic, S. Jouanne-Pin, C. Remoue, C. Bonneuil, and I. Goldringer. 2012. On-farm dynamic management of genetic diversity: the impact of seed diffusions and seed saving practices on a population-variety of bread wheat. Evolutionary Applications 5(8):779-795. http://dx.doi.org/10.1111/ j.1752-4571.2012.00257.x

Tindall, D. B., and J. L. Robinson. 2017. Collective action to save the ancient temperate rainforest: social networks and environmental activism in Clayoquot Sound. Ecology and Society 22(1):40. https://doi.org/10.5751/ES-09042-220140

Vance-Borland, K., and J. Holley. 2011. Conservation stakeholder network mapping, analysis, and weaving. Conservation Letters 4 (4):278-288. http://dx.doi.org/10.1111/j.1755-263x.2011.00176.x

Violon, C., M. Thomas, and E. Garine. 2016. Good year, bad year: changing strategies, changing networks? A two-year study on seed acquisition in northern Cameroon. Ecology and Society 21(2):34. http://dx.doi.org/10.5751/es-08376-210234

Wasserman, S., and K. Faust. 1994. Social network analysis. Methods and applications. Cambridge University Press, Cambridge, UK. http://dx.doi.org/10.1017/cbo9780511815478

Wencélius, J., M. Thomas, P. Barbillon, and E. Garine. 2016. Interhousehold variability and its effects on seed circulation networks: a case study from northern Cameroon. Ecology and Society 21(1):44. http://dx.doi.org/10.5751/es-08208-210144

White, D., and U. Johansen. 2005. Network analysis and ethnographic problems: process models of a Turkish nomad clan. Lexington Books, Lanham, Maryland, USA. 